\title{
DESIGNING HYDRAULIC AIR CHAMBER IN WATER TRANSMISSION SYSTEMS USING GENETIC ALGORITHM
}

\author{
Abdorahim Jamal', Mohsen Najarchi', S. Mohammad Mehdi Najafi Zade² \\ 1 Department of Civil Engineering, Islamic Azad University, Arak Branch, Arak, Iran, e-mail: abdorahimjamal@ \\ gmail.com, m-najarchi@iau-arak.ac.ir \\ 2 Department of Mechanic Engineering, Islamic Azad University, Arak Branch, Arak, Iran, e-mail:m-najafizadeh@ \\ iau-arak.ac.ir
}

Received: 2016.01 .22

Accepted: 2016.07.27

Published: 2016.09.01

\begin{abstract}
Transient flow control in Water Transmission Systems (WTS) is one of the requirements of designing these systems. Hence, among control equipment, air chambers offer the best solution to control transient flow effects, i.e. both prevents water column separation and absorbs pressure increase. It is essential to carry out an accurate and optimized design of air chambers, not only due to high costs of their manufacturing but also their important protective role. Accordingly, hydraulic design parameters comprise tank volume, diameter of nozzle and coefficients of inflow and outflow of nozzle. In this paper, it is intended to optimize these parameters in order to minimize manufacturing costs. On the other hand, maximum and minimum pressures in main pipeline are considered as constraints which shall fall in allowed range. Therefore, a model has been developed which is a combination of a hydraulic simulation model of WTS and an optimization model based on genetic algorithm. This model is first applied to WTS of Dehgolan-Ghorveh plain as a case study. Results of this research demonstrate that based on suggested model, negative wave creation and pressure increase in pipeline is prevented as well as decrease in manufacturing costs of air chamber.
\end{abstract}

Keywords: water transmission, transient flow, genetic algorithm, air chamber, water hammer, cavitation.

\section{INTRODUCTION}

There are many water transmission systems in the world used to transmit vast capacity of surface water. The annual cost to build and maintain water transmission systems are typically millions of dollars [1].The importance of economic feasibility of projects on the one hand, and the fundamental role of these systems in the usage of limited water resources on the other hand, the economic and optimization design for water transmission is taken into consideration for years.

The powerful optimization models have been created to determine hydraulic specification of water transmission systems, such as diameter of pipes, thickness and material of pipe, etc. [2-9]. The main usage of these models is design and analysis of water transmission systems in steady conditions. But because of design complexity in conditions of transient flow, studies in this area are scarce while almost all water transmission systems in their operation life encountered with conditions of transient flow. Several factors can cause transient flow in water transmission systems that the most important of them are: turning pumps on or off, opening or closing the valves, filling the empty pipelines and bursting the pipes. Among them, stopping pumps suddenly causes the most critical conditions in the water transmission systems.

Each of these factors or combination of them can lead to the disruption of the water transmission system and sometimes destroy the whole system. Therefore, one of the most important fac- 
tors of structural protection in the design of water transmission pipelines is the control of effects of transient flow. Water hammer and fluid column separation are two transient flow destructive effects which are often controlled using instruments such as air chamber, surge tanks, bypass pipes, flywheel and some control valves.

Using air chamber is one of the best methods to control effects of transient flows. These chambers based on their mechanism, in addition to control low pressure and prevent fluid column separation, are used against to water hammer caused by high pressures. But on the other hand, the construction cost these chambers, is very high so that an air chamber with a common volume of $50 \mathrm{~m}^{3}$ will cost more than $\$ 50,000$. So accurate computations for designing an air chamber must be done.

But common design methods include complex steps of analysis and design, so proposing an acceptable design needs several months of an engineering team actively. Since in these methods, optimizing a plan is usually a process which changes parameters of design and compares design results with allowable constraints using trial and error method. So because of numerous iterations to find an optimum design, optimization tools should be used.

In this paper, using a meta-heuristic algorithm, namely Genetic Algorithm (GA), one of the most important and expensive components of water transmission systems, namely air chamber, is optimized. Because of successful experiences of GA in water industry, this algorithm is used [10-15]. The main advantage of this heuristic algorithm is its ability in finding the optimum global result for objective function. The objective function in this research includes construction cost of air chamber in water transmission system of Dehgolan-Ghorveh plain which must be minimized. Dehgolan-Ghorveh plain's water transmission system is used as a case study because of evaluating and comparing its information with proposed model. The model proposed in this paper is a combination of a hydraulic model for simulating water transmission systems and an optimizer model for finding optimum values of effective hydraulic parameters on performance of air chamber. These parameters include tank volume, diameter of nozzle and coefficients of inflow and outflow of nozzle.

The proposed model in this paper could prevent water hammer phenomenon and cavitation as well as could save on costs of air chamber manu- facturing. Using this model in similar projects could decrease million dollars in costs of design, construction and operation of water transmission systems annually.

\section{AIR CHAMBER MECHANISM IN TRANSIENT FLOW CONDITIONS}

The most critical scenario for creating transient flow in transmission systems is caused by emergency operation of the pump (e.g. turning off by power cut suddenly). In this case, rotational speed of the pump will be decreased compared to fluid inertia of drift pipe because of low inertia. Head and pumping discharge will be decrease after the rotational speed decreased, so positive and negative waves are created in drift and suction pipes respectively and led toward upstream and downstream.

In this regard, water hammer caused by positive wave propagation can break valves and pipes. If hydraulic gradient line be lower than level of transmission line in each point, it is possible that by negative wave propagation, phenomenon of fluid column separation will happen.

So water hammer and fluid column separation are two transient flows which necessary facilities must be considered to prevent them in design process of water transmission systems. In this regard, application of air chamber is such that when driving force of the pump is interrupted and discharge decreased consequently, compressed air inside tank leads water to pipeline forcedly and decreases probability of cavitation. On the other hand, after a short time some water is led through pipeline to tank reversely and decrease extra pressure caused by water hammer.

To achieve this operation, air chamber should have some specifications which considers a ratio of the water supply volume to initial air is the most important of them. This subject is important because firstly, the water supply volume should be enough so that when the water flow from tank to pipeline, the tank should not be empty and air does not enter the pipeline and secondly, the initial air inside tank is not so little, which does not effect on the process of flow pressure reduction in pipeline.

Another specification of air chamber is attention to diameter of connected pipe between tank and pipeline (nozzle) and attention to coefficient of inflow and outflow of the nozzle. This 
is important because the water flow entry path to tank should be able to make high head loss and consequently, decrease the pressure of water flow in pipeline against high pressures. On the other hand, the water flow exit path from air chamber should be such that water can circulate in pipeline to compensate pressure reduction comfortably, in condition of negative wave. Recommended head loss ratio of the hole for inflow to outflow is 2.5:1.

In addition to two above specifications, the total volume of tank that has direct relation with construction cost of air chamber, is an important factor should be minimized. Total volume is calculated using (1) as follows:

$$
V_{\text {total }}=V_{0 a i r}+\Delta V+V^{\prime}
$$

where: $V_{\text {oair }}$ - the volume of initial air in steady conditions,

$\Delta V$ - maximum increment of tank air volume when the flow is transient,

$V^{\prime}$ - useless volume of water in tank considered to ensure the air does not enter into pipeline and the surge tank deos not empty.

It is noticeable useless volume of water in surge tank should be about $10 \%$ of tank volume that sumation of it and maxmimum increament of air volume result the value of the water supply volume.

Now, to achieve the minimum volume of tank, trial and error method is used. Thus, for initial volume of water $\left(V_{\text {oair }}\right)$, the diameter of nozzle and coefficients of inflow and outflow of it, initial values are considered. Then, the result of this plan include velocity and pressure in different junctions with allowable values, is controlled. This process is repeated frequently. Finally, the best values for decision variables of problem are achieved with respect to available constraints.

But this process takes a long time and there is always probability of loss of valid results. So in this paper, due to the above problem, a novel model is proposed which makes the easier and more accurate process of air chamber design. This model is a combination of a hydraulic model for simulation of water transmission systems and an optimization model, based on GA, for determining optimum values of effective hydraulic factors on air chamber operation.

In the next section, for describing hydraulic simulation model of water transmission systems, boundary conditions of air chambers for analysis using characteristic method are described briefly.

\section{NUMERICAL ANALYSIS OF AIR CHAMBERS}

In the pumped pipelined systems it is recommended to control transient flows caused by power cutting the air chamber installed in drift pump. An air chamber, according to Figure 1, is a tank where there is compressed air in the top part and water in its bottom. To limit inflow and outflow of air chamber, a nozzle is set between tank and pipeline. In junction of nozzle and pipeline, characteristic equations will be as follows:

$$
\begin{aligned}
& Q_{P_{i, n+1}}=C_{P}-C_{\dot{u}} H_{P_{i, n+1}} \\
& Q_{P_{i, n+1}}=C_{n}+C_{\dot{u}+1} H_{P_{i+1,1}}
\end{aligned}
$$

If we do not consider the loss, based on relation between energy and continuity, we will have:

$$
\begin{gathered}
H_{P_{i, n+1}}=H_{P_{i+1,1}} \\
Q_{P_{i, n+1}}=Q_{P_{i+1,1}}+Q_{P_{o f f}}
\end{gathered}
$$

In this equation, $Q_{P_{\text {orf }}}$ is a flow through the nozzle.

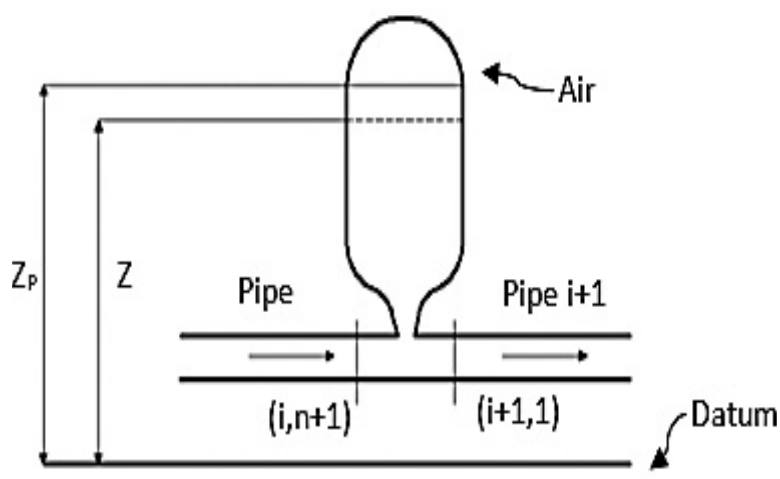

Fig. 1. A schematic design for air chamber

If we assume that the existing air in top part of air chamber is trapped, based on the thermodynamics rules for full gas we have:

$$
H_{P_{\text {air }}}^{*} \forall_{P_{\text {air }}}^{m}=C
$$

where: $H_{P_{a i r}}^{*}$ and $\forall_{P_{a i r}}^{m}$ are absolute pressure and volume of trapped air in the last time step of analysis.

$m-$ is the air expansion coefficient is usually considered 1.2 and

$C$ - is a constant number is calculated using $C=\forall_{0_{\text {air }}^{m}}^{m} H_{0_{\text {air }}}^{*}$.

Index of zero in above equation imply on initial conditions in steady state. In these conditions, the head loss for flow through nozzle is calculated as follows: 


$$
h_{P_{\text {orf }}}=C_{\text {orf }} Q_{P_{\text {orf }}}\left|Q_{P_{\text {orf }}}\right|
$$

where: $C_{\text {orf }}$-is the nozzle loss coefficient,

$h_{P_{o f f}}-$ is equal to amount of head loss of nozzle.

Notice the amount of nozzle loss coefficient is different for inflow and outflow. Based on above equations, the volume of trapped air can be calculated using 8 and 9:

$$
\begin{gathered}
H_{P_{\text {air }}}^{*}=H_{P_{i, n+1}}+H_{b}-Z_{P}-h_{P_{o r f}} \\
\forall_{P_{\text {air }}}=\forall_{\text {air }}-A_{C}\left(Z_{P}-Z\right) \\
Z_{P}=Z+0.5\left(Q_{\text {orf }}+Q_{P_{\text {orf }}}\right) \frac{\Delta t}{A_{C}}
\end{gathered}
$$

where: $H_{b}-$ is relative pressure,

$A_{C}-$ horizontal sectional area of air chamber,

$Z, Z_{p}$ - the heights of water level in air chamber from base in the first and last time step,

$Q_{\text {orp }}, \forall_{\text {air }}$ - flows through the nozzle and air volume in the first time step.

So there are 9 equations altogether, equations 2 to 10 which include 9 unknown variables: $Q_{P_{i, n+1}}$, $Q_{P_{i+1,1}}, Q_{P_{o f f}}, H_{P_{i, n+1}}, H_{P_{i+1,1}}, h_{P_{o f f}}, \forall_{P_{a i r}}, H_{P_{a i r}}^{*}$ and $Z_{p}$. To simplify solving these equations, some of the unknown variables are omissible. So with replacing equations 2 to 4 in equation 5, we will have:

$$
Q_{P_{o f f}}=\left(C_{P}-C_{n}\right)-\left(C_{a_{i}}+C_{a i+1}\right) H_{P_{i, n+1}}
$$

Similarly, with replacing equations 8 and 9 in equation 6 :

$\left(H_{P_{i, n+1}}+H_{b}-Z_{P}-C_{o r f} Q_{P_{o r f}} \mid Q_{P_{o f f}}\right)\left[\forall_{\text {air }}-A_{C}\left(Z_{P}-Z\right)\right]^{m}$

Equations 10 to 12 have three unknown variables include $Q_{P_{o r f}}, H_{P_{i, n+1}}$ and $Z_{p}$. Deleting $H_{P_{i, n+1}}$ and $Z_{p}$ from these equations results a nonlinear equation for $Q_{P_{\text {of }}}$ which for solving it we can use a repeating technique like Newton-Rafson. Definite amount of $Q_{o r f}$ in the first time step could be applied as the initial guess for starting this repeating process.

\section{SPECIFICATIONS OF DEHGOLAN- -GHORVEH PLAIN'S WATER TRANSMISSION PIPELINE}

Transmitting water from Azad dam to Dehgolan-Ghorveh plain is for supplying water of agriculture lands of Dehgolan's plain and water requirements section located on the route of the transmission line. In this research, part of the water transmission system between first pumping station and the second pumping station's tank has considered as case study. This part of transmission system includes $5200 \mathrm{~m}$ of steel pipes ST37II with a diameter of $1600 \mathrm{~mm}$ and wall thickness of $16 \mathrm{~mm}$ which starts form first pumping station with height of $1593.5 \mathrm{~m}$ and ends at second pumping station with height of $1800.2 \mathrm{~m}$. Capacity of line will be 3750 liters per second and total height in this section will be $217 \mathrm{~m}$. Roughness coefficient is according to Hazen-Williams equation and has considered 125 in all parts of transmission pipeline. Movement velocity of pressure wave in each section has calculated according to pipe's specifications and modeling has been done assuming the sudden failure of pumps. We are watching the development of negative pressure according to modeling done in all parts of transmission pipeline, so the only way to prevent water hammer and cavitation is using air chamber.

\section{PROPOSED MODEL}

In this paper, to design an optimum air chamber in water transmission systems, a simulator model linked to GA is used. Thus velocity and pressure of water flow in pipes are calculated using simulator model. Performance and accuracy of hydraulic simulation of flow conditions in pipelines have a great effect on finding an optimum design. In this paper, characteristic method, as mentioned before, is used to simulate flow and GA is used for optimization. In this algorithm, each chromosome (vector of problem decision variables) shows an air chamber and the target of problem is minimizing of construction cost. Whatever the construction cost of this chamber, which is according to tank volume, be less, the fitness will be more and chance of using related information to this tank for producing the next air chamber will increase. The listed constraints in (13) which is influenced by tank volume $(V)$, diameter of nozzle $\left(D_{n}\right)$ and coefficients of inflow and outflow of the nozzle $\left(C_{\text {Qin }}, C_{\text {Qout }}\right)$ are added to objective function as penalty function to convert the mentioned conditional problem to unconditional problem.

$$
\begin{gathered}
P_{\min }, P_{\max }=f\left(V, D_{n}, C_{\text {Qin }}, C_{\text {Qout }}\right) \\
P_{\min }<P_{i}<P_{\max }
\end{gathered}
$$


where: $P_{\min }, P_{\max }$ - are maximum and minimum pressure constraints to prevent equipment from damages and cavitation,

$P_{i}$-shows amount of pressure in the junction of pipeline.

The connection between simulator model and optimizer (Figure 2) is as follows:

Phase 1: Reading input necessary information include information of pipeline (the number of pipes, the number of junctions, ground level and etc.) and information of GA (the number of populations, the number of generations, probability of mutation and crossover, method of selection, fitness function and etc.).

Phase 2: Generating initial population randomly (since in this paper, the objective is optimizing volume of air chamber, diameter of nozzle pipe and determining optimum value of inflow and outflow loss coefficients from chamber, the initial population of these variables produced randomly).

Phase 3: $i=1$.

Phase 4: Performing bellow steps for all answer in population:

I. $k=1$.

II. Calculating the amount of flow and pressure in permanent conditions.

III. Hydraulic simulation for calculating pressure and discharge at desired time span.

IV. Calculating cost of air chamber.

V. $K=k+1$.

VI. If $k<$ npop go to II.

Phase 5: $i=i+1$.

Phase 6: If $i>n g e n$ go to phase 13 .

Phase 7: Calculating fitness function for each air chamber.

Phase 9: Selecting the chromosomes according to their fitness.

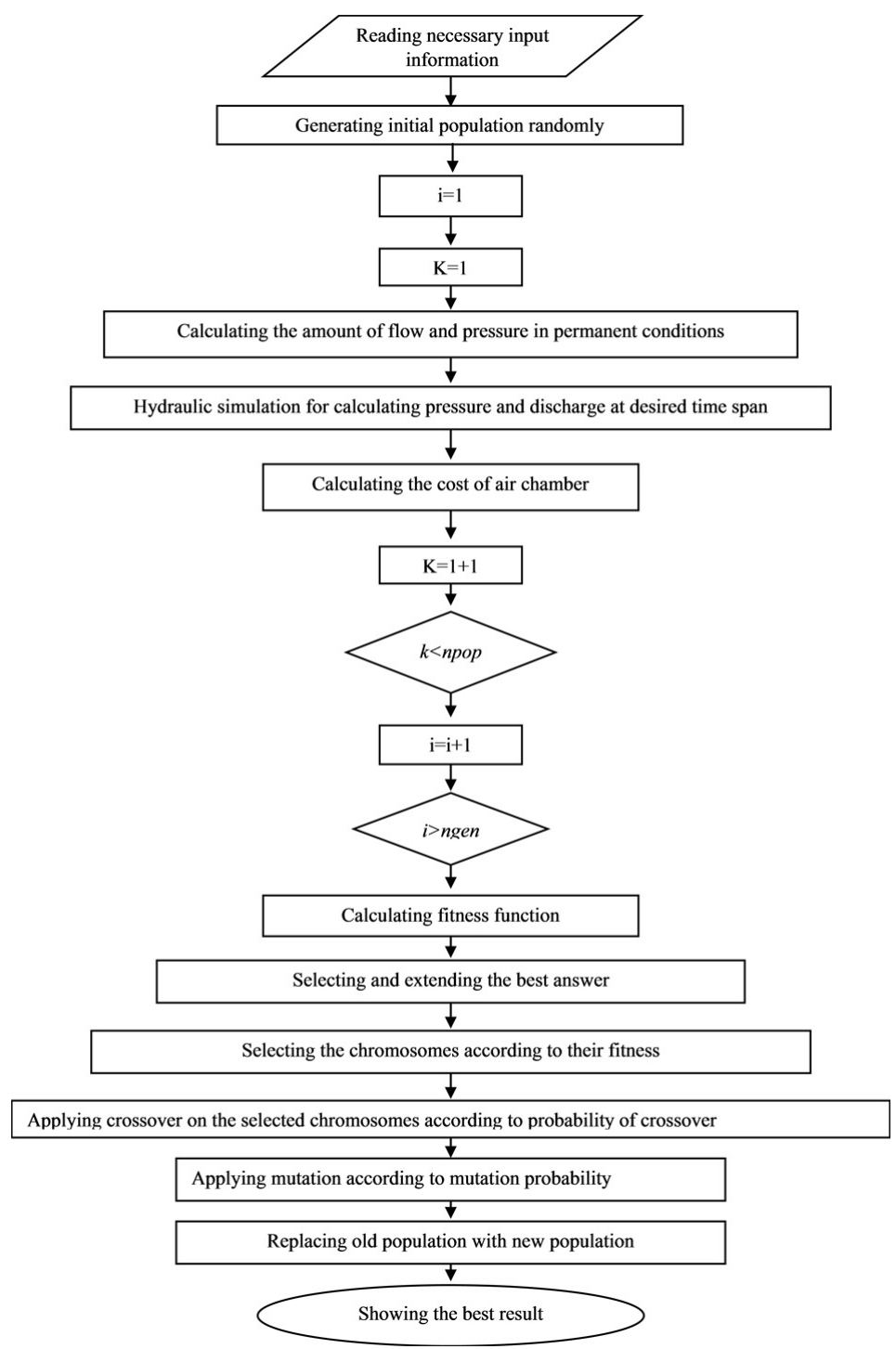

Fig. 2. Flow chart of proposed model 
Phase 10: Applying crossover on the selected chromosomes according to probability of crossover.

Phase 11: Applying mutation according to mutation probability.

Phase 12: Replacing the old generation with new generation and repeating phases 4 to 12 .

Phase 13: Showing the best result (optimum values).

\section{RESULTS}

Figure 3 shows the minimum and maximum pressure in pipelines for optimum results designed using GA. So the water transmission system of Dehgolan-Ghorveh plain needs an air chamber with some specifications (Table 1) in optimum conditions.

Figure 4 shows variation diagram of objective function value based on the number of times that
GA needs simulation of transmission system in the process of designing.

\section{CONCLUSIONS}

Simulation of transient flow in water transmission systems was done using characteristic method which air chambers defined as tool to protect these systems against water hammer and cavitation. In this paper, GA was used to optimize air chamber volume, nozzle pipe's diameter and determining optimum value of inflow and outflow loss coefficient. One part of Dehgolan-Ghorveh plain's water transmission system was selected as a case study. The results of this paper as a new and meta-heuristic method, in addition to prevent extra increment of costs with considering constraints of minimum and maximum to prevent damage to pipelines, try to increase safety of water transmission systems.

Table 1. Summary of optimized air chamber information

\begin{tabular}{|c|c|c|c|}
\hline Tank volume $\left[\mathrm{m}^{3}\right]$ & Nozzle diameter $[\mathrm{mm}]$ & Coefficient of inflow & Coefficient of outflow \\
\hline 31 & 300 & 0.45 & 0.8 \\
\hline
\end{tabular}

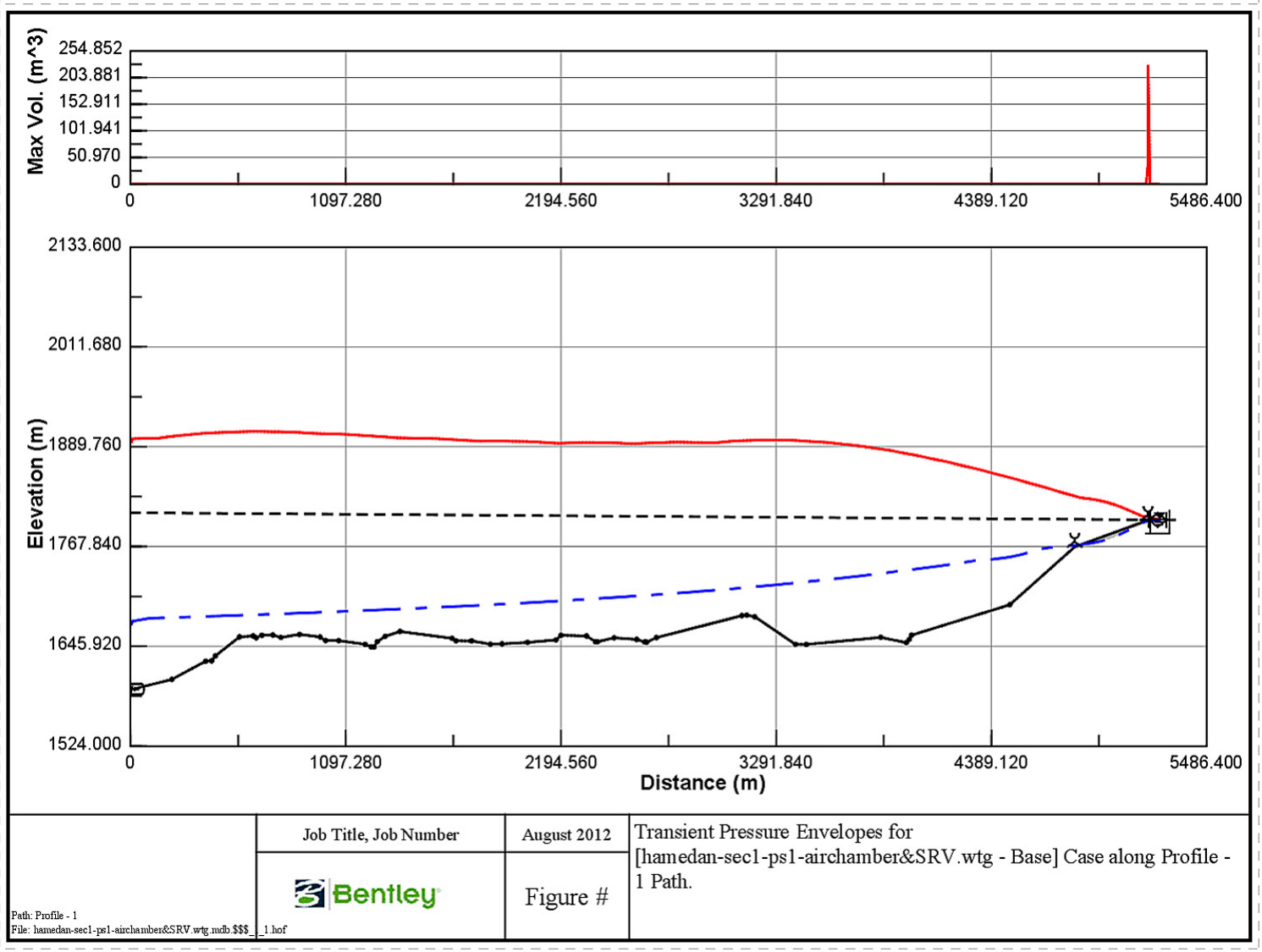

Fig. 3. Curve of maximum and minimum pressure variation 


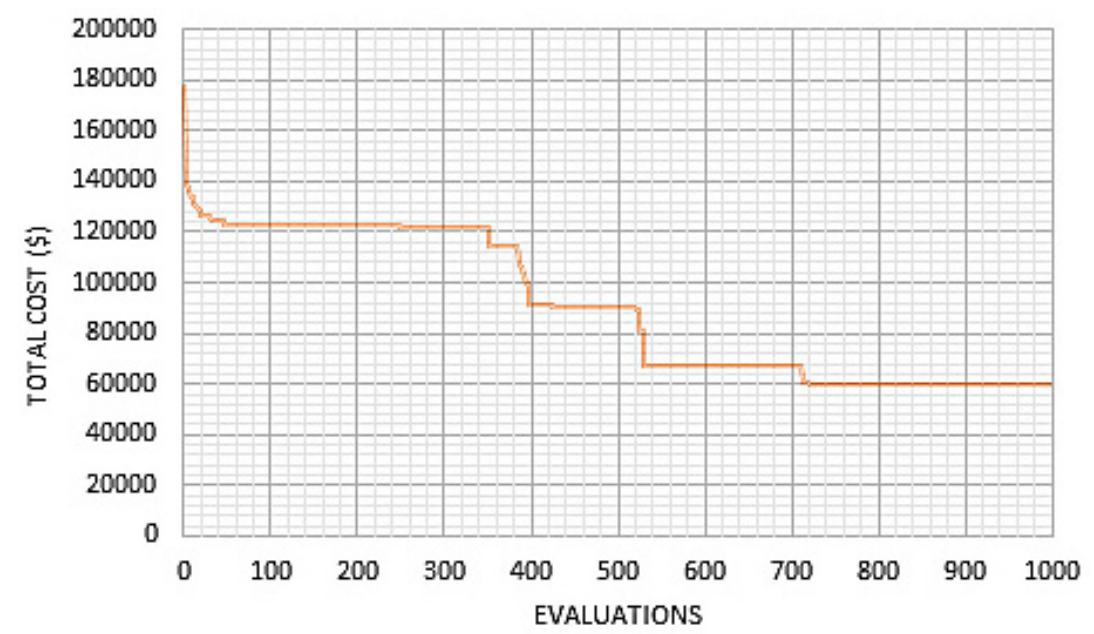

Fig. 4. Variation of cost-the number of generation (GA)

\section{REFERENES}

1. Lingridy S, Funk J.E. and Wang H. Genetic algorithm in optimizing transient suppression device. Proceeding of the 20th International Conference on Water Resources Engineering and Water Resources Planning and Management. Visakapatnam, India, 2000, 205-211.

2. Swamee P., Kumar V., Khanna P. Opimization of dead end water distribution systems. J Environmental Engineering Division, ASCE, 99(2), 1973, 123-134.

3. Osborne J., James, L. Marginal economics applied to pipeline design. J Transportation Division, ASCE, 99(3), 1973, 637-653.

4. Koh E., Maidment D. Microcomputer promrams for designing water systems. J American Water Works Association; 76(7), 1984, 62-65.

5. Gupata I., Hussan M., Cook J. Linear programming analysis of water supply system. Transactions of the American Institute of Industrial Engineers, 1(1), 1969, 200-214.

6. Deb A.K. Least cost design of water mains in series. J Environmental Engineering Division, ASCE, 99(EE3), 973, 405-409.

7. Dancs L. Sizing force mains for economy. Water and Sewage Works, No. R-127, 1977.
8. Cowan J. Checking trunk main designs for costeffectiveness. Water and Water Engineering, 75(908), 1971, 385-386.

9. Canales Ruiz R. Optimal design of gravity flow water conduits. J Hydraulic Division, ASCE, 106(HY9), 1980, 1489-1502.

10. Afshar M.H., Rohani M. Optimal Operation of Pipeline System Using Genetic Algorithm. IEEE Congress on Evolutionary Computation, CEC 2009.

11. Afshar M.H., Marino M.A. A convergent genetic algorithm for pipe network optimization. scientia Iranica, 12(4), 2005, 392-401.

12. Afshar M.H., Jabbari E. Simultaneous layout and pipe size optimization of pipe networks using genetic algorithm. Arabian Journal for Science and Engineering, 33(2B), 2007, 391-409.

13. Afshar M.H., Ghasemi M.R. An efficient selection operator for genetic search of pipe networks opimal design. International Journal of Civil Engineering, 3(2), 2005,78-88.

14. Afshar M.H. Application of a compact genetic algorithm to pipe network optimization problems. scientia Iranica, 16(3), 2009, 264-271.

15. Afshar M.H. Evaluation of selection algorithms for simultaneous layout and pipe size optimization of water distribution networks. Scientia Iranica, 14(1), 2007, 23-32. 